\title{
Real-time earthquake monitoring for tsunami warning in the Indian Ocean and beyond
}

\author{
W. Hanka ${ }^{1}$, J. Saul ${ }^{1}$, B. Weber ${ }^{1, *}$, J. Becker ${ }^{1, *}$, P. Harjadi ${ }^{2}$, Fauzi $^{2}$, and GITEWS Seismology Group ${ }^{1}$ \\ ${ }^{1}$ Deutsches GeoForschungsZentrum GFZ, Telegrafenberg, 14473 Potsdam, Germany \\ ${ }^{2}$ Badan Meterologi, Klimatologi dan Geofisika (BMKG), Jl. Angkasa 1 No. 2, Kemayoran, Jakarta, Indonesia \\ *now at: Gempa GmbH, Telegrafenberg, 14473 Potsdam, Germany
}

Received: 16 August 2010 - Revised: 16 November 2010 - Accepted: 17 November 2010 - Published: 20 December 2010

\begin{abstract}
The $M_{\mathrm{w}}=9.3$ Sumatra earthquake of 26 December 2004 generated a tsunami that affected the entire Indian Ocean region and caused approximately 230000 fatalities. In the response to this tragedy the German government funded the German Indonesian Tsunami Early Warning System (GITEWS) Project. The task of the GEOFON group of GFZ Potsdam was to develop and implement the seismological component. In this paper we describe the concept of the GITEWS earthquake monitoring system and report on its present status. The major challenge for earthquake monitoring within a tsunami warning system is to deliver rapid information about location, depth, size and possibly other source parameters. This is particularly true for coast lines adjacent to the potential source areas such as the Sunda trench where these parameters are required within a few minutes after the event in order to be able to warn the population before the potential tsunami hits the neighbouring coastal areas. Therefore, the key for a seismic monitoring system with short warning times adequate for Indonesia is a dense real-time seismic network across Indonesia with densifications close to the Sunda trench. A substantial number of supplementary stations in other Indian Ocean rim countries are added to strengthen the teleseismic monitoring capabilities. The installation of the new GITEWS seismic network - consisting of 31 combined broadband and strong motion stations - out of these 21 stations in Indonesia - is almost completed. The real-time data collection is using a private VSAT communication system with hubs in Jakarta and Vienna. In addition, all available seismic realtime data from the other seismic networks in Indonesia and other Indian Ocean rim countries are acquired also directly by VSAT or by Internet at the Indonesian Tsunami Warning Centre in Jakarta and the resulting "virtual" network of more
\end{abstract}

Correspondence to: W. Hanka (hanka@gfz-potsdam.de) than 230 stations can jointly be used for seismic data processing. The seismological processing software as part of the GITEWS tsunami control centre is an enhanced version of the widely used SeisComP software and the well established GEOFON earthquake information system operated at GFZ in Potsdam (http://geofon.gfz-potsdam.de/db/eqinfo.php). This recently developed software package (SeisComP3) is reliable, fast and can provide fully automatic earthquake location and magnitude estimates. It uses innovative visualization tools, offers the possibility for manual correction and re-calculation, flexible configuration, support for distributed processing and data and parameter exchange with external monitoring systems. SeisComP3 is not only used for tsunami warning in Indonesia but also in most other Tsunami Warning Centres in the Indian Ocean and Euro-Med regions and in many seismic services worldwide.

\section{Introduction}

\subsection{The great Andaman earthquake}

The tsunami tragedy following the great $M_{\mathrm{w}}=9.3$ Andaman earthquake of 26 December 2004 (Stein and Okal, 2005) prompted a great effort to establish tsunami warning systems for the Indian Ocean rim countries. It also changed dramatically the scope of the GEOFON programme (http: //geofon.gfz-potsdam.de) of the GFZ German Research Centre for Geosciences as it took on the task to design and implement the land based seismic component of the GermanIndonesian Tsunami Warning System (GITEWS, Rudloff et al., 2009) as central part of the Indonesian Tsunami Warning System InaTEWS. In this task it benefitted from GEOFON's expertise in Internet-based near real-time data acquisition, rapid near real-time earthquake information (http:// geofon.gfz-potsdam.de/geofon/new/eq_inf.html) and virtual seismic network management. Within any tsunami early

Published by Copernicus Publications on behalf of the European Geosciences Union. 
warning concept, but mainly for a warning system for nearfield tsunamis, the earthquake monitoring system plays a central role (Hanka et al., 2006). The time available to warn the population in the adjacent coastal areas after a tsunami has been generated by a large earthquake in the Sunda trench is extremely short since the expected tsunami travel times are only of the order of 20-40 min or even less in some places. Therefore, tsunami watch or warning bulletins should be issued preferably within $5 \mathrm{~min}$ in order to be able to initiate timely civil protection measures. These bulletins will initially be based primarily on rapidly determined earthquake parameters and on selected pre-calculated tsunami scenarios which fit the initial seismic parameters (Behrens et al., 2010). Other sensor data such as buoy and tide gauge data will usually not be available within such a short time frame but will be needed later-on to either validate a warning status or to cancel it. Indian Ocean wide tsunamis will primarily be generated from large Sunda trench earthquakes (Lauterjung et al., 2010). A second potential source zone for tsunamogenic thrust events is the Makran trench, but due to the limited source dimensions it will potentially create local or regional tsunamis. Success in tsunami early warning for Indonesia will also benefit the other Indian Ocean rim countries within the IOTWS (Indian Ocean Tsunami Warning System, coordinated by the Intergovernmental Oceanographic Commission of UNESCO, IOC) as relevant information about ocean-wide tsunami obtained in Indonesia may be timely distributed to the other potentially affected countries. Therefore international cooperation is the key for Indian Ocean tsunami warning and for GITEWS, both for primary data exchange (e.g. seismic data and earthquake parameters) but also for the exchange of tsunami watch bulletins. The same is true for the EuroMed area, where preparations for the establishment of a tsunami warning system for the NE Atlantic, the Mediterranean and adjacent seas (NEAMTWS, Tinti, 2009) also have been initiated. As an extension of the GITEWS project, the GFZ brings in its expertise and achievements from the Indian Ocean to this undertaking (Hanka and Lauterjung, 2009).

\subsection{The GEOFON Programme before 2005}

The GEOFON programme was founded already in 1992. Its original task was to provide high quality data for seismological research projects by implementing a permanent global network with regional densifications and performing temporary deployments mainly for structural research and to operate a comprehensive data archive. GEOFON tried to achieve this goal through intensive cooperation and knowledge distribution. It plays a major role in European and global coordination of broadband seismology and contributed substantially to ORFEUS (Observatories and Research Facilities for European Seismology, (http://www.orfeus-eu.org) and the FDSN (Federation of Digital Seismograph Networks, http://www.fdsn.org). GEOFON stations represent an impor- tant part of the global FDSN backbone network, and GEOFON also initiated and supported national network upgrades in many - mainly European - countries. With very effective methods in station design, data collection and processing it became attractive for many partners to join GEOFON efforts in producing and sharing high quality seismological broadband data. A major milestone was the development of the SeedLink protocol as part of GEOFON's SeisComP (Seismological Communication Processor) concept (Hanka et al., 2000), permitting connection of digitizers and data loggers from all major manufacturers and all major acquisition systems, conversion of the native data formats to MiniSEED and uniform transmission, acquisition and archival of heterogeneous network data. The open realtime data exchange among European networks was substantially improved when SeisComP was distributed throughout Europe within the EC project MEREDIAN (van Eck et al., 2004), in which the VEBSN (Virtual European Broadband Seismic Network) was formed as its major achievement. Automatic real-time data processing became part of SeisComP in 2003. A fully automatic prototype earthquake monitoring system mainly based on European VEBSN data was operational at GFZ on Boxing Day 2004, when the SumatraAndaman earthquake occurred. Just 12 min after the rupture started the automatic system published the first earthquake information on the GEOFON earthquake information web page (http://geofon.gfz-potsdam.de/db/eqinfo.php). This was one of the first publicly available notifications of this event worldwide and was for this reason often cited. However, due to the use of mainly European stations the location was not very accurate and as only saturating rapid magnitudes were implemented in SeisComP at that time, the published magnitude values for $m_{\mathrm{b}}$ and $M_{\mathrm{L}}$ heavily underestimated $(M=7.0)$ the true magnitude. Nevertheless, the existing expertise and code base in earthquake monitoring provided a strong basis to develop the seismological part of GITEWS.

\section{The concept}

Rapid seismological data processing naturally plays a major role in concepts for earthquake generated tsunamis. The standard method for tsunami early warning by seismological means is the usage of decision matrices where the alert level is determined only by hypocentre location and moment magnitude. For the GITEWS project the realization of this traditional approach was regarded to be the first step only. However, non-standard is in any case the envisaged time line of 5 min instead of 15-20 min - as e.g. for the Pacific Tsunami Warning System, designed to warn distant coasts from farfield tsunamis rather than adjacent coasts from the near-field ones - and represents a major challenge. With the possible exception of Japan and Alaska such an ambitious warning time line was not state-of-the-art before GITEWS. 
Table 1. GITEWS seismic station list. The last three stations on the list are remaining to be installed in 2011.

\begin{tabular}{|c|c|c|c|c|c|}
\hline Code & Name & Latitude & Longitude & Altitude & Opening \\
\hline $\mathrm{BKB}$ & Balikpapan, Kalimantan, Indonesia & -1.1073 & 116.9048 & 110 & $2009 / 160$ \\
\hline BKNI & Bangkinang, Sumatra, Indonesia & 0.3262 & 101.0396 & 65 & $2008 / 120$ \\
\hline BNDI & Bandaneira, Indonesia & -4.5224 & 129.9045 & 16 & $2008 / 186$ \\
\hline CISI & Cisomped, Java, Indonesia & -7.5557 & 107.8153 & 544 & $2008 / 203$ \\
\hline FAKI & Fak Fak, Irian Jaya, Indonesia & -2.91925 & 132.24889 & 136 & $2008 / 336$ \\
\hline GENI & Genyem, Irian Jaya Indonesia & -2.5927 & 140.1678 & 47 & $2009 / 330$ \\
\hline GSI & Gunungsitoli, Nias, Indonesia & 1.3039 & 97.5755 & 107 & $2005 / 275$ \\
\hline JAGI & Jajag, Java, Indonesia & -8.4702 & 114.1521 & 171 & $2008 / 203$ \\
\hline LHMI & Lhokseumave, Sumatra, Indonesia & 5.2288 & 96.9472 & 3 & $2008 / 060$ \\
\hline LUWI & Luwuk, Sulawesi, Indonesia & -1.0418 & 122.7717 & 6 & $2008 / 070$ \\
\hline MMRI & Maumere, Flores, Indonesia & -8.6357 & 122.2376 & 137 & $2006 / 313$ \\
\hline MNAI & Manna, Sumatra, Indonesia & -4.3605 & 102.9557 & 154 & $2006 / 208$ \\
\hline PMBI & Palembang, Sumatra, Indonesia & -2.9024 & 104.6993 & 25 & $2005 / 340$ \\
\hline SANI & Sanana, Moluccas, Indonesia & -2.0496 & 125.9881 & 30 & $2009 / 337$ \\
\hline SAUI & Saumlaki, Tanimbar, Indonesia & -7.9826 & 131.2988 & 110 & $2009 / 237$ \\
\hline SMRI & Semarang, Java, Indonesia & -7.04915 & 110.44067 & 203 & $2006 / 305$ \\
\hline SOEI & Soe, Timor, Indonesia & -9.7553 & 124.2672 & 1047 & $2006 / 347$ \\
\hline TNTI & Ternate, Indonesia & 0.7718 & 127.3667 & 43 & $2007 / 005$ \\
\hline TOLI & Tolitoli, Sulawesi, Indonesia & 1.1214 & 120.7944 & 86 & $2008 / 182$ \\
\hline UGM & Wanagama, Indonesia & -7.9125 & 110.5231 & 350 & $1995 / 235$ \\
\hline DAMY & Dhamar, Yemen & 14.5725 & 44.3917 & 2488 & $2008 / 261$ \\
\hline SOCY & Socotra, Yemen & 12.51952 & 53.98742 & 804 & $2009 / 022$ \\
\hline SBV & Sambava, Madagascar & -13.4584 & 49.9212 & 65 & $2009 / 323$ \\
\hline VOI & Vohitsoka, Madagascar & -22.0260 & 46.7059 & 993 & $2009 / 330$ \\
\hline HMDM & Hanimaadhoo, Maldives & 6.77314 & 73.18216 & 1 & $2008 / 022$ \\
\hline KAAM & Kaadhehdhoo, Maldives & 0.49264 & 72.99486 & 1 & $2008 / 029$ \\
\hline MALK & Mahakanadarawa, Sri Lanka & 8.39682 & 80.54254 & 113 & $2010 / 100$ \\
\hline HALK & Hakmana, Sri Lanka & 6.0885 & 80.6805 & 42 & $2010 / 113$ \\
\hline PLAI & Plampang, Sumbawa, Indonesia & -8.7569 & 117.8583 & 40 & pl. 2011 \\
\hline LDWK & Lodwar, Kenya & 3.4217 & 35.3621 & 670 & pl. 2011 \\
\hline KIBK & Kibwezi, Kenya & -2.3597 & 38.0443 & 789 & pl. 2011 \\
\hline
\end{tabular}

\subsection{The seismic network}

The envisaged warning time line enforces a certain geometry for the GITEWS seismological network. Initial considerations of installing 2 or 3 small aperture seismic arrays across Indonesia rather than a dense single station network were withdrawn because of the mandatory need to alert within $5 \mathrm{~min}$. Travel times of 3-4 min from Sunda trench sources to relatively distant arrays for example in Sumatra, Java, Kalimantan or Irian Jaya are incompatible with a 5 min total time limit. Instead a dense network of up to 160 high quality seismic stations, consisting of broadband and strong motion sensors more or less equally spaced all over Indonesia was suggested, of which 156 stations are presently implemented, although not all in the previously planned locations. So far 20 of these stations were installed by GITEWS (one still to be installed, Table 1). All data are telemetered in real-time to the Indonesian InaTEWS Tsunami Warning Centre at the main GITEWS partner institution BMKG (Indonesia's Agency for
Meteorology, Climatology, and Geophysics) in Jakarta. Private VSAT links on an Indonesian satellite (Telkom-2) with a private hub at BMKG are used for data transmission. In case of full failure of the non-GITEWS stations the German subnetwork alone should be able to locate an earthquake within the 5-min time limit, the GITEWS sites are spread fairly even across the Indonesian archipelagos (Fig. 1). 105 more stations were installed by the Indonesian partners themselves, another 15 by the Japanese National Research Institute for Earth Science and Disaster Prevention (NIED), 10 by the Chinese Earthquake Agency (CEA), 5 by the Comprehensive Test Ban Treaty Organization (CTBTO) and one from the US IRIS Global Seismic Network.

Setting up a high quality seismic network in Indonesia is a special challenge. Hard rock sites are rare, logistics are difficult and security is a matter of concern. Thus, for most stations easyly accessible and secure sites had to be chosen, many of them at BMKG premises or other public locations. The site conditions influence the data quality, which is in 


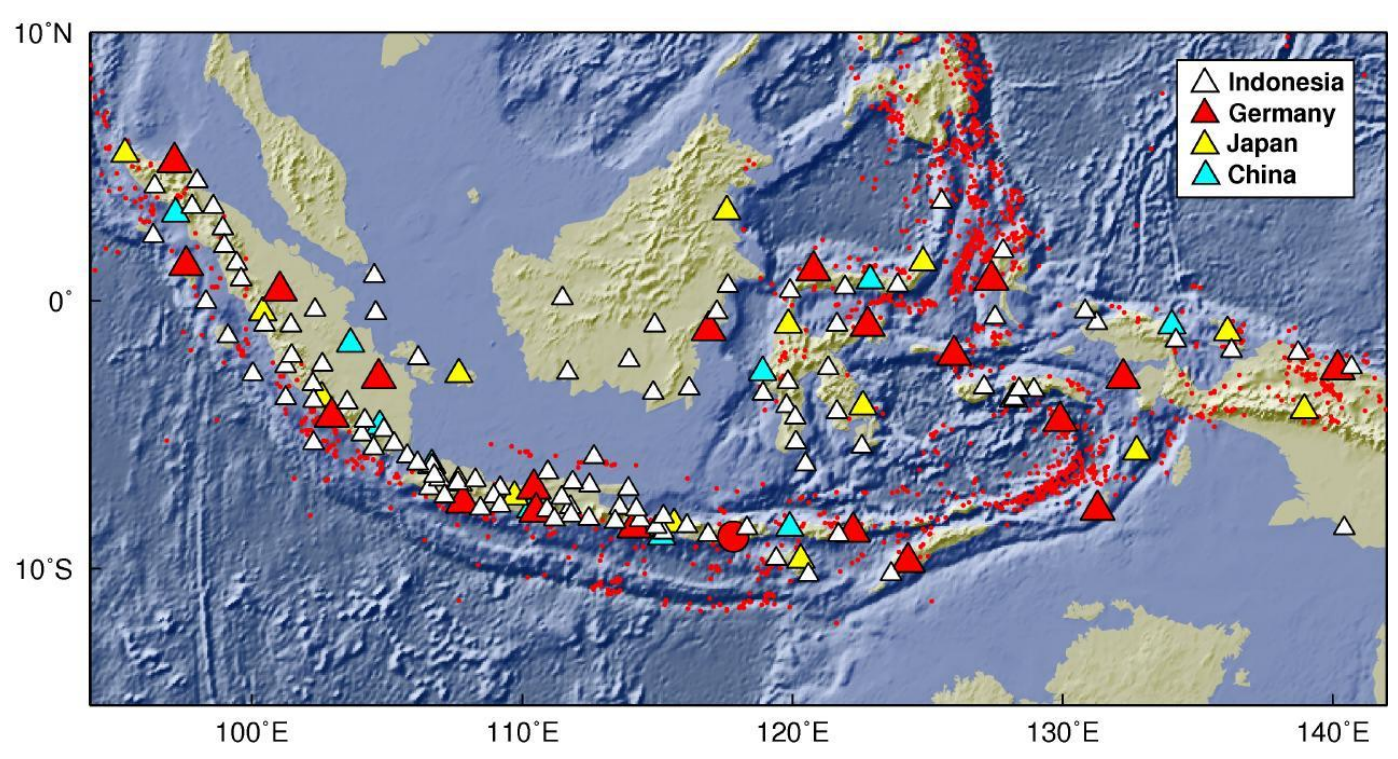

Fig. 1. New seismological broadband network in Indonesia, including GITEWS (Germany), BMKG (Indonesia), NIED (Japan), and CEA (China) stations. The red circle indicates the last GITEWS station presently under preparation.

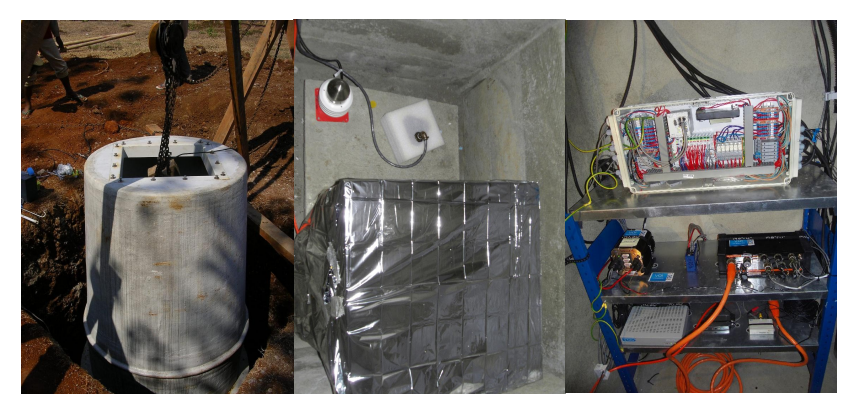

Fig. 2. Typical Vault Design - Left: GITEWS standard fibre seismic vault; Centre: station equipment with seismic sensors - broadband seismometer (in thermal insulation cover) and accelerometer; Right: electronic devices.

many cases relatively poor. Only very few sites meet normal GEOFON standards. However, it does not make much sense to set up a station in a quiet remote location unless longterm operation can be guaranteed, particularly if the purpose of the seismic network is primarily tsunami warning and the detection of smaller earthquakes is - at least from GITEWS' perspective - of lower priority. The basic principle in station design, besides using GEOFON standard seismological equipment (STS-2 seismometer, Q330 digitizer, SeisComP station processor) was sustainability, minimum requirements for local assistance and maximum remote control. Full solar power, reliable backup communication (BGAN, a robust mobile satellite terminal), web-cam, water level control, environmental observation system and a remote hardware control unit completed the sophisticated design (Fig. 2). Three different vault types were realized for the GITEWS stations.
Five sites in Sumatra and Java are equipped with prefabricated fiber vaults with an iron-armed base plate, designed and constructed in Germany and shipped to Indonesia (Fig. 2). These underground vaults consist of two chambers, a lower one for the seismic sensors and an upper one for the electronics. The whole construction is tightly embedded in concrete. As this construction is fully watertight and almost airtight inside, humidity ( $\sim 25 \%$ of the outside) - and thus corrosion - is very low, even the smallest animals cannot enter and it can be expected that the normally very high equipment failure rate in tropical areas should be significantly reduced. Only the VSAT dish and the solar power system remain outside this construction. Unfortunately, for logistical reasons, for the more remote areas of Indonesia conventional concrete vault constructions had to be used, consisting of either a more sophisticated underground vault (5 stations) or a simple surface housing (10 stations) with only minimum burial of sensors.

Beside the creation the core of the Indonesian network, GITEWS tried to fill gaps in other parts of the Indian Ocean, namely in Sri Lanka, Maldives, Yemen, Kenya and Madagascar, where two stations each have been installed (though both stations in Kenya are not yet installed, Table 2, Fig. 3). Although travel times from the Sunda trench to these stations exceed $5 \mathrm{~min}$ (except for Sri Lanka and Maldives), these stations provide important data to improve the preliminary estimation of source depth, moment tensor and rupture propagation from teleseismic distances and monitor the Western part of the Indian Ocean including the Makran trench area.

Additionally, also within GITEWS, the existing GEOFON stations in the Mediterranean and NE Atlantic are going to be upgraded to GITEWS standard for the surveillance of the 
Table 2. Comparison of seismic parameters and publication times of BMKG for the major tsunamogenic earthquakes in Indonesia since the installation of SeisComP3 as routine processing software with the interim tsunami warning centres for the Indian Ocean at PTWC and JMA and with the global earthquake information of NEIC and GFZ.

\begin{tabular}{|c|c|c|c|c|c|}
\hline \multicolumn{6}{|c|}{ Bengkulu 2007-09-12 11:10:24 } \\
\hline & Time (min) & Mag & Latitude & Longitude & Depth \\
\hline BMKG & $04: 21$ & 7.9 & $4.66 \mathrm{~S}$ & $101.11 \mathrm{E}$ & 10 \\
\hline PTWC & 14 & 7.9 & $4.5 \mathrm{~S}$ & $101.3 \mathrm{E}$ & \\
\hline JMA & 26 & 7.9 & $4.5 \mathrm{~S}$ & $101.3 \mathrm{E}$ & \\
\hline NEIC & 17 & 7.9 & $4.369 \mathrm{~S}$ & $101.557 \mathrm{E}$ & 15 \\
\hline GFZ (auto) & $06: 10$ & 7.9 & $4.66 \mathrm{~S}$ & $101.13 \mathrm{E}$ & 10 \\
\hline GFZ (man) & 25 & 8.0 & $4.57 \mathrm{~S}$ & $101.34 \mathrm{E}$ & 32 \\
\hline \multicolumn{6}{|c|}{ Manokwari 2009-02-03 19:43:55 } \\
\hline & Time $(\min )$ & Mag & Latitude & Longitude & Depth \\
\hline \multirow[t]{2}{*}{ BMKG } & $04: 34$ & 7.2 & $0.42 \mathrm{~S}$ & $132.94 \mathrm{E}$ & 10 \\
\hline & $10: 23$ & 7.9 & $0.58 \mathrm{~S}$ & $132.85 \mathrm{E}$ & 48 \\
\hline PTWC & 12 & 7.5 & $0.7 \mathrm{~S}$ & $132.8 \mathrm{E}$ & 33 \\
\hline JMA & n.a. & n.a. & n.a. & n.a. & n.a. \\
\hline NEIC & 29 & 7.6 & $0.510 \mathrm{~S}$ & $132.783 \mathrm{E}$ & 35 \\
\hline GFZ (auto) & $05: 03$ & 8.0 & $0.52 \mathrm{~S}$ & $132.86 \mathrm{E}$ & 10 \\
\hline GFZ (man) & 37 & 7.9 & $0.57 \mathrm{~S}$ & $132.81 \mathrm{E}$ & 32 \\
\hline \multicolumn{6}{|c|}{ Padang 2009-09-30 10:16:10 } \\
\hline & Time $(\min )$ & Mag & Latitude & Longitude & Depth \\
\hline BMKG & $03: 58$ & 7.6 & $0.84 \mathrm{~S}$ & $99.65 \mathrm{E}$ & 71 \\
\hline PTWC & 10 & 7.7 & $0.9 \mathrm{~S}$ & $99.9 \mathrm{E}$ & \\
\hline JMA & 22 & 7.7 & $0.9 \mathrm{~S}$ & $99.9 \mathrm{E}$ & \\
\hline NEIC & 14 & 7.9 & $0.797 \mathrm{~S}$ & $99.925 \mathrm{E}$ & 85 \\
\hline GFZ (auto) & $02: 53$ & 7.1 & $0.86 \mathrm{~S}$ & $99.63 \mathrm{E}$ & 66 \\
\hline GFZ (man) & 15 & 7.8 & $0.80 \mathrm{~S}$ & $99.87 \mathrm{E}$ & 84 \\
\hline \multicolumn{6}{|c|}{ Sinabang 2010-04-06 22:15:02 } \\
\hline & Time $(\min )$ & Mag & Latitude & Longitude & Depth \\
\hline BMKG & $04: 51$ & 7.2 & $2.33 \mathrm{~N}$ & $97.02 \mathrm{E}$ & 34 \\
\hline PTWC & 7 & 7.5 & $2.2 \mathrm{~N}$ & $97.1 \mathrm{E}$ & \\
\hline JMA & n.a. & n.a. & n.a. & n.a. & n.a. \\
\hline NEIC & 12 & 7.8 & $2.2 \mathrm{~N}$ & $97.0 \mathrm{E}$ & 46 \\
\hline GFZ (auto) & 05:01 & 7.4 & $2.28 \mathrm{~N}$ & $96.99 \mathrm{E}$ & 33 \\
\hline GFZ (man) & 10 & 7.6 & $2.27 \mathrm{~N}$ & $97.05 \mathrm{E}$ & 46 \\
\hline
\end{tabular}

NEAMTWS area as well as the teleseismic monitoring of the Indian Ocean. As the footprint of the Telkom-2 satellite covers a large part of South Asia, the Indonesian VSAT system is used also for the data transfer from Sri Lanka and the Maldives directly to the Jakarta warning centre. The data from the stations in the Western Indian Ocean as well as those in the Mediterranean are collected by 3 different satellites linked to GFZ via a second GITEWS VSAT hub at a provider site in Austria and routed to Indonesia and other tsunami centres by Internet. In addition, data from other Indian Ocean networks (Australia, Malaysia, Thailand, South Africa, the IRIS GSN and the French GEOSCOPE network) are imported also through GFZ via Internet. Presently, the virtual seismic network for the Indian Ocean available at BMKG consists of about 230 stations, while the global virtual network at GFZ (GEOFON Extended Virtual Network, GEVN) meanwhile comprises more than 700 stations.

\subsection{The SeisComP3 software}

As data sharing is essential for accurate earthquake monitoring, data from totally different instruments used in the various networks and sub-networks needs to be unified and integrated into one single processing scheme. Moreover, reliable rapid near real-time automatic data processing, visualization of its results and quick graphical review tools required the development of a special new software package 


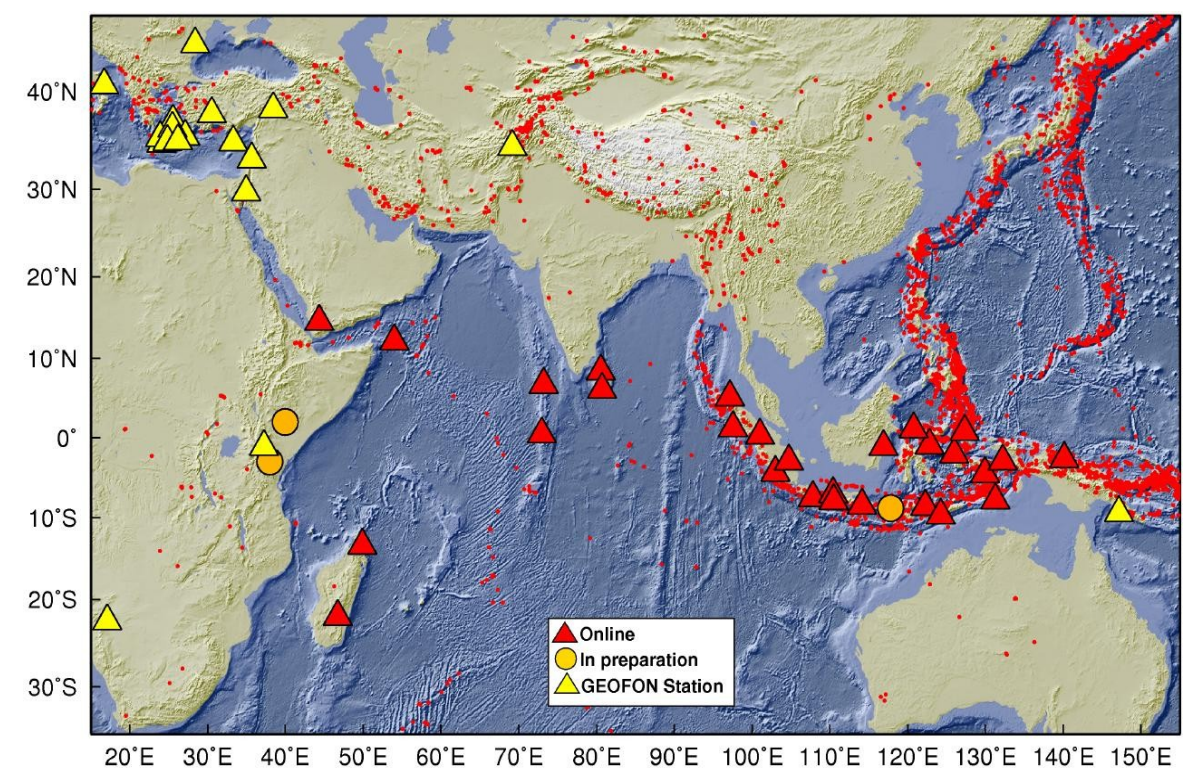

Fig. 3. GEOFON and GITEWS stations in the Indian Ocean region. 28 GITEWS stations are presently installed, 3 more will be completed in 2011 (see also Table 1).

(SeisComP3) as none of the then-existing seismic analysis packages - commercial (e.g. Antelope, www.brtt.com) and non-commercial (e.g. Earthworm, Johnson et al., 1995, together with EarlyBird, Luckett et al., 2008) - could fully provide this under the specific GITEWS time constraints and with the required long-term perspective. Although based on a new innovative software architecture and consisting of mostly newly written codes, the SeisComP3 (SC3) software package can be regarded as an extension of the well established SeisComP1 (SC1) and 2 (SC2) versions (Hanka et al., 2000) (http://geofon.gfz-potsdam.de/geofon/seiscomp). It combines generalized data acquisition, data quality control, data archival, real-time data transfer protocol, automatic procedures to determine location, depth, magnitudes and rupture parameters and sophisticated alerting and visualization tools (Fig. 4). Although 24/7 operation is mandatory at tsunami warning centres, the basic parameter calculation is at first carried out fully automatically, but visual supervision and where necessary manual interaction is possible at each stage (Fig. 5). Audible and visual alerting tools are implemented to guarantee the attention of the seismic experts in the warning centre. They can interact at any time and improve the automatic results. The well accepted data acquisition and transfer package SeedLink and the data archive access tool ArcLink remained basically unchanged from SC2 while the automatic picker and location python modules of SC2 were re-written in $\mathrm{C}++$ for reasons of better integration and performance.

SC3 has a highly modular design and provides several new developed modules for automatic and interactive data processing. A basic automatic system of SC3 consists of modules for quality control, picking, location, amplitude and magnitude calculation, waveform quality assessment and event and station parameter management. All modules are implemented as stand-alone programs connected through messaging and a central database. This architecture allows replacements of any module of the processing chain. The interactive part of the system provides graphical user interfaces for visualizing the overall situation in respect to earthquakes locations and station status in a map, real time trace and event summary display. As SC3 is designed for fast interactive analysis, it provides a toolkit for analysing the earthquake epicenter, depth and magnitudes. The included manual picker is optimized for rapid verification of pre-calculated picks from strong earthquake signals providing e.g. automatic loading of newly acquired real-time data with picks associated to the ongoing event, automatic amplitude scaling and trace alignment. However, it also allows conventional offline analysis of small and moderate earthquakes.

A messaging system based on the TCP/IP network protocol is used to distribute the processing results among the modules. TCP/IP allows the operation of the individual modules at different computers connected via LAN or WAN. The messaging system is based on the open source toolkit "Spread" (http://www.spread.org). It can be configured to handle different target groups. SeisComP3 uses groups for all major processing result types like PICK, AMPLITUDE, LOCATION, MAGNITUDE etc. A module connects to the target group which contains the required information and sends the results to the corresponding target group. For example the auto location module listens to messages with the PICK group and sends the calculated hypocentres to 


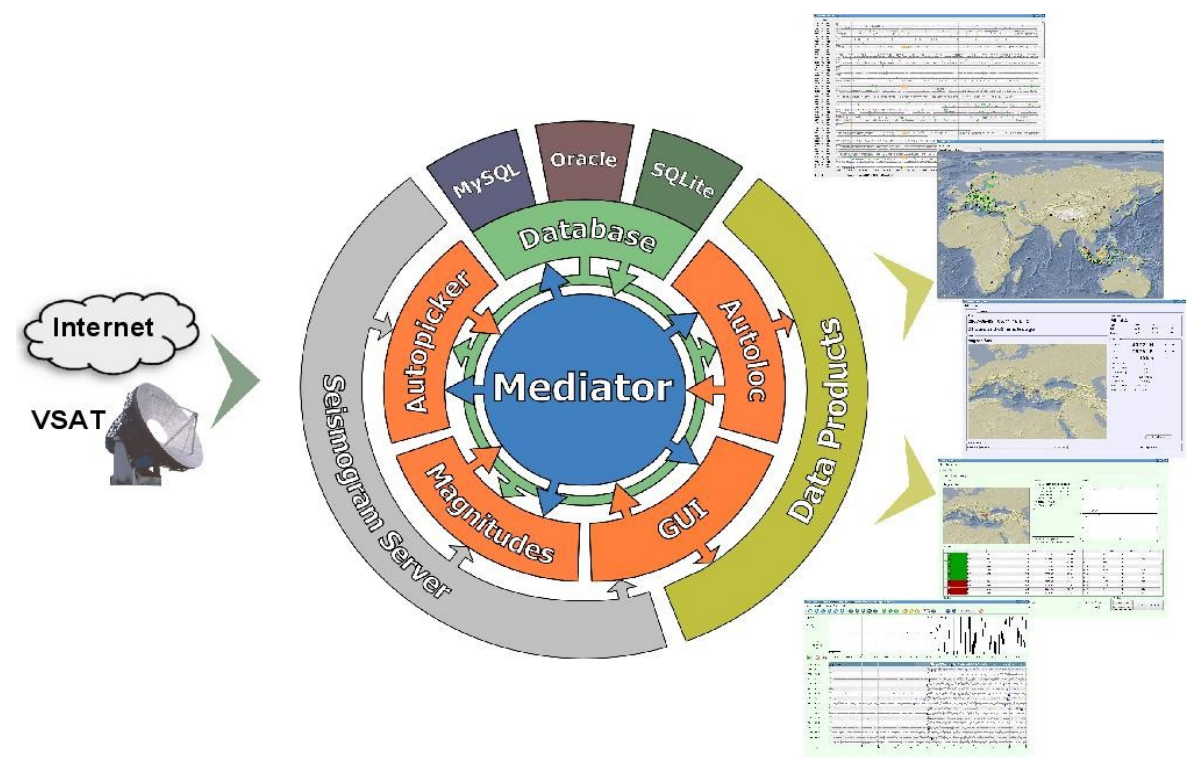

Fig. 4. SeisComP3 basic architecture. The individual modules are connected with each other and with the central data base by a messaging system (Mediator). The waveforms are provided by a combined seismogram service, consisting of a SeedLink (real-time data feeds) and ArcLink (local or distributed archive access) server.

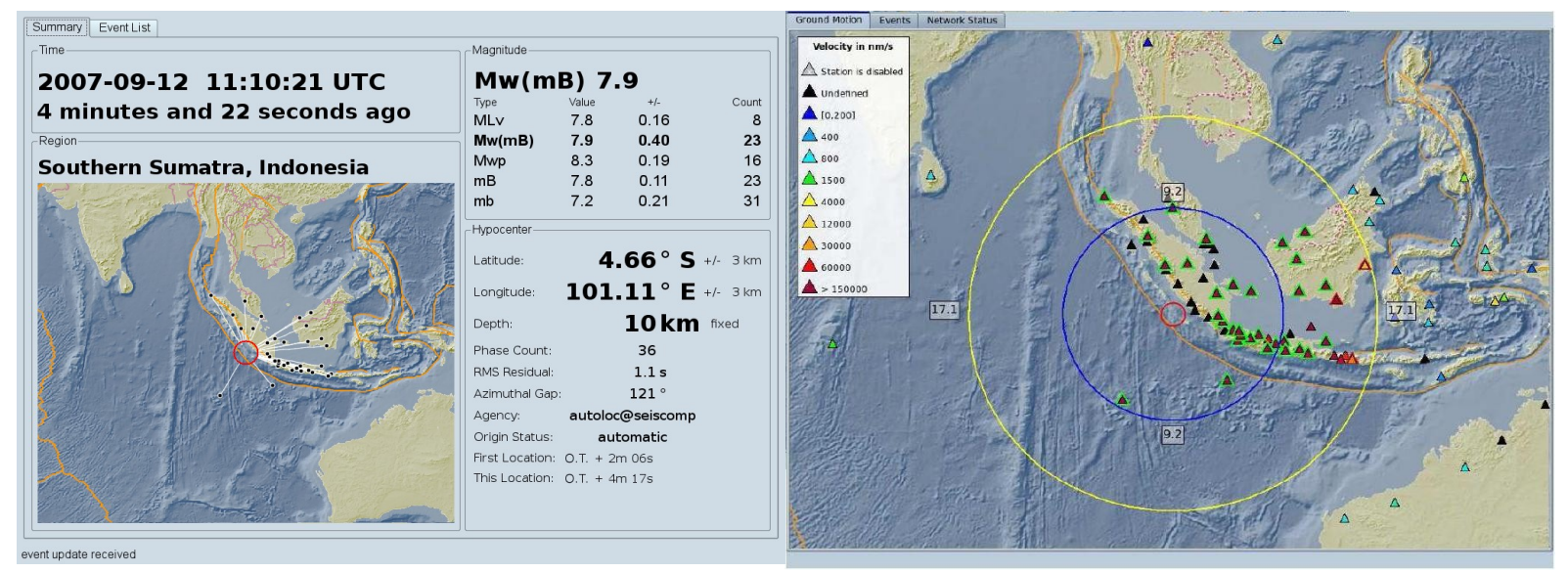

Fig. 5. Sample SeisComp3 graphic user interfaces (event summary and situation map views) as observed during the Bengkulu earthquake (2007-09-12).

the LOCATION group. The results are communicated in form of a unified data model, which is a derivative model of QuakeML (a proposed new XML standard for the representation of seismological parameters, https://www.quakeml.org), but optimized for the work-flow of SeisComP3. This data model is also used as the database scheme. SC3 supports SQL based databases such as presently MYSQL and POSTGRESQL. While the modules themselves have only read-access, the central component of the messaging system called "scmaster" is the only module writing to the database. It ensures that all information communicated in so called "notifier"-messages are written in the database. For waveform access SC3 uses its own protocols: SeedLink for (near) real-time data feeds and ArcLink for data from online archives. Both have become a de-facto global standard.

SC3 also offers an innovative distributed network approach, which allows connection between various systems and exchange of both waveform data and processing results. In principle any seismic centre could be linked this way, even those operating other processing software. While SeedLink can also be used as a real-time waveform server for foreign analysis software (all major other packages such as 


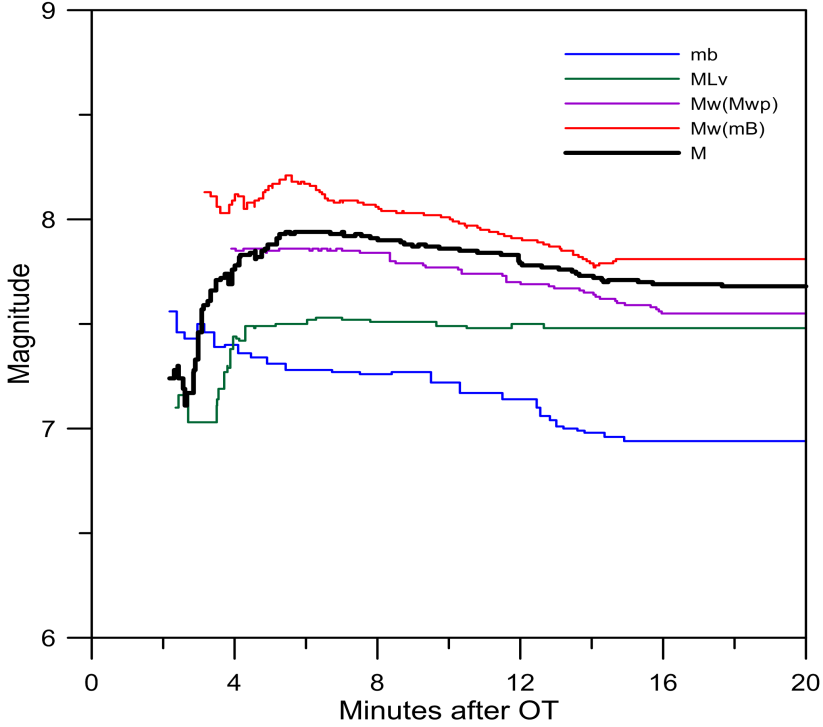

Fig. 6. Evaluation of individual magnitudes types with time for the Padang M=7.9 earthquake (2009-09-30).

Earthworm and Antelope support it) the parameter exchange could be carried out through QuakeML import and export. In the case of the InaTEWS warning system in Jakarta the QuakeML export is also used to forward the SC3 processing results to the decision support system DSS (Steinmetz et al., 2010), which is the central part of the overall GITEWS warning system. DSS is connected to all sensor sub-systems (seismic, sea level, continuous GPS), to the simulation data base and to the dissemination systems by the so-called tsunami service bus (TSB, Fleischer et al., 2010). In the DSS, the final decision on tsunami watch or warning levels or cancellations are made and bulletins are issued.

$\mathrm{SC} 3$ is written in the $\mathrm{C}++$ programming language. Additional support for the Python scripting language is achieved by using special wrapper functions. SC3 provides substantial development support for custom modules, namely $\mathrm{C}++$ libraries to ease the development of fully integrated new SC3 modules and wrappers for more loosely coupled modules in other programming languages. Common tasks like waveform and database access, message communication, math operations etc are already implemented and can be re-used by custom modules.

Besides the professional and highly efficient software design, magnitudes that allow a rapid quantification of very large earthquakes are an essential ingredient to effective tsunami warning. In SC3, we adopted the original Gutenberg \& Richter body-wave magnitude $m_{\mathrm{B}}$, which uses the full broadband $\mathrm{P}$ wave signal. It therefore does not suffer from the spectral saturation of the, more well- known narrow-band, $m_{\mathrm{b}}$. A new $m_{\mathrm{B}}$ calibration function allows $m_{\mathrm{B}}$ estimates starting at distances as low as $5^{\circ}$ (Bormann and Saul, 2008). In a second step $m_{\mathrm{B}}$ is mapped to $M_{\mathrm{w}}\left(m_{\mathrm{B}}\right)$ by using a "correction function" derived by comparing the moment magnitude from GCMT with the corresponding $m_{\mathrm{B}}$ for hundreds of earthquakes. This magnitude performs comparably well to other P-wave based $M_{\mathrm{w}}$ estimators like $M_{\mathrm{wp}}$ (Tsuboi et al., 1999) - which is also determined by SC3 but is much simpler to compute and less sensitive to data errors such as small gaps, which are common in real-time processing. The use of $m_{\mathrm{B}}$ as a proxy for $M_{\mathrm{w}}$ thus allows quick and robust magnitude estimates after as little as $2 \mathrm{~min}$ and provides the basic tool for earthquake size quantification in SC3. Similar to estimating $M_{\mathrm{w}}$ from $m_{\mathrm{B}}$, the $M_{\mathrm{wp}}$ calculated by SeisComP3 is mapped to $M_{\mathrm{w}}$ using the "correction function" of Whitmore et al. (2002). An extension of $m_{\mathrm{B}}$ to $m_{\mathrm{Bc}}$ (cumulative $m_{\mathrm{B}}$ for giant quakes with $M>8.5$, Bormann and Saul, 2009) is under development. Other standard magnitudes $\left(M_{\mathrm{L}}, m_{\mathrm{b}}, M_{\mathrm{S}}(\mathrm{BB})\right)$ are also computed in parallel, others are planned (e.g. $\left.M_{\mathrm{S}}(20)\right)$. SeisComP3 allows manual selection of any of these multiple magnitudes as the preferred event magnitude. By default a time dependent composite magnitude " $M$ " derived as weighted average from all well-determined individual magnitudes is set as preferred. Thus all automatic solutions are associated with " $M$ " values. The composite magnitude " $M$ " can be considered as an attempt to obtain a "best" magnitude estimate at any time, especially in the first minutes after origin time when estimates are available from only a few stations:

$M=\Sigma w_{i} m_{i} / \Sigma w_{i}$ with $w_{i}=a_{i} n_{i}+b_{i}$

where $i$ is the magnitude type index, $w_{i}$ weighting factors, $m_{i}$ the network magnitude of type $i, n_{i}=$ number of station magnitudes of type $i$ and $a_{i}, b_{i}$ are selectable coefficients.

Often large discrepancies exist between the individual magnitude types, especially within the first minutes when the average values consist of only few individual measurements. This often makes it difficult to select the "right" one. The advantage of this composite approach is a smooth development of magnitude with time (Fig. 6) with cannot be achieved with a dynamic switching of the preferred magnitude type. Due to varying processing time windows and applicable distance ranges for $m_{\mathrm{b}}\left(30 \mathrm{~s}, 5-105^{\circ}\right), m_{\mathrm{B}}\left(90 \mathrm{~s}, 5-105^{\circ}\right), M_{\mathrm{wp}}$ $\left(90 \mathrm{~s}, 3-105^{\circ}\right), M_{\mathrm{L}}$ (distance dependent, $\left.0-1000 \mathrm{~km}\right), M_{\mathrm{bmg}}$ (0-20 $0^{\circ}$, a simple and quick magnitude modified from the Japanese standard magnitude $M_{\mathrm{jma}}$ ) and $M_{\mathrm{s}}(\mathrm{BB})$ (distance dependent, $2-160^{\circ}$ ) a varying number of individual station magnitudes of each type exists.

Since the GITEWS early warning concept does not only aim at issuing unspecific warnings affecting large areas as it would be the case with the simple decision matrix approach - but to forecast precisely inundation heights for individual coastal ranges, the GITEWS seismology group investigated more sophisticated analysis methods which could help to characterize the tsunami generating earthquake model in more detail. This could enable the DSS to put reasonable constraints on the selection of pre-calculated tsunami 
scenarios. Ideally, the seismological sub- system should not only calculate epicentre location, depth and moment magnitude, but also the moment tensor and the direction, speed and length of the rupture. However, it was clear from the project inception, that robust algorithms for automatic application of such methods needs at first to be fully developed and that their routine application needs substantially longer data time windows and more processing time than what is achievable within the tight time limit for the initial alert. Therefore the development of such "slow" modules had to have a lower priority compared to "fast" methods like $M_{\mathrm{w}}$ estimation from $\mathrm{P}$ waves. Meanwhile, a moment tensor (MT) tool based on matching of windowed (P, S, surface wave) pre-calculated Green's functions became operational within SeisComP3. It provides automatic MT solutions for regional and teleseismic distances within about 15 min with the possibility for interactive graphics supported optimization. Another MT option for teleseismic distances is the SC3 based KIWI Autopilot tool using the KIWI Tools developed by Heimann and Cesca (http://kinherd.org) which provides both point source and extended source solutions in a SC3 environment about 20-25 min after origin time.

In a similar approach the teleseismic rupture tracking algorithm of Krüger and Ohrnberger (2005) was implemented within the GITEWS project for routine application in a SC3 environment at Potsdam University (Roessler et al., 2010). It requires a huge number of data streams from a large globally distributed virtual network forming a number of virtual regional seismic arrays and a lot of computing power. It is therefore not easily applicable at most data processing centres. In this method, the data acquisition and processing takes about 25-30 min and thus the results could only be used for the later refinement of the initial assumptions on the tsunami generating earthquake source rather than for constraining the first scenario selection. A substantially faster rupture tracking algorithm based on automatic polarization analysis of regional recordings was recently developed at GFZ (Bayer et al., 2010). It is expected that after implementation in SC3 this method will provide at least an initial idea of the rupture direction within the 5-10 min time line, but presently it is not yet available as a routinely applicable tool. The SeisComP3 moment tensor and rupture tracking tools are still under testing and so far not integrated in the routine processing at GFZ or BMKG.

\section{Implementation}

\subsection{Indonesia}

Unlike the major part of the tsunami warning control centre software, an early prototype version of SeisComP3 was already available for installation and testing at BMKG in early May 2007. Just before the Bengkulu earthquake series (September 12/13, 2007, Magnitudes $M_{\mathrm{w}}=8.4$ and 7.9) an updated version for routine service became available. Since at this time, the system already processed the realtime data of a large virtual seismic network - about 100 stations within and around Indonesia - and it was already possible to achieve a very short processing time for the realtime data analysis for these events. For the first earthquake on 12 September 2007, which with a final moment magnitude of 8.4 had the highest potential to produce a tsunami, a first internal "heads-up" alert was issued just under $2 \mathrm{~min}$ after origin time; a first estimate of location, depth range and magnitude was available after 02:30 min stating already that a $M>7$ shallow earthquake had occurred at a location close to the final one. A stable solution with a moment magnitude estimate of 7.9 based on 25 stations was published after 04:20 min, leading to the first tsunami alert ever issued by BMKG within the $5 \mathrm{~min}$ limit. Also in global context this success represents a remarkable milestone. The pre-IOTWS alerts as presently issued temporarily by Pacific Tsunami Warning Center (PTWC) and the Japanese Meteorological Agency (JMA) reached BMKG after 14 and 26 min, respectively, while the US National Earthquake Information Service (NEIC) solution became available after $19 \mathrm{~min}$, all showing very similar results to the BMKG solution (see Table 2).

Since September 2007 a number of potentially tsunamogenic earthquakes with magnitudes above 7.5 have occurred in Indonesia and have been analysed equally well with the GITEWS SeisComP3 system at BMKG. These events include Manokwari (Irian Jaya, 2009-02-03, $M_{\mathrm{w}}=7.6$ ), Padang (Central Sumatra, 2009-09-30, $M_{\mathrm{W}}=7.9$ ) and Sinabang (Northern Sumatra, 2010-04-06, $M_{\mathrm{w}}=7.8$ ). The initially published solutions of PTWC, JMA, NEIC and GFZ are comparable to those rapidly disseminated by BMKG (Table 2) and prove that SC3 allows the 24/7 InaTEWS service to perform well and to be capable of issuing tsunami alerts below the $5 \mathrm{~min}$ threshold, well ahead of any other agency without suffering any substantial drop in accuracy. It can also be recognized from this table that PTWC and NEIC have also significantly improved their response times since 2007, which is most likely due to optimization of processing procedures but is also supported by importing the real-time data feeds of the new GITEWS stations from GFZ.

\subsection{GFZ Potsdam}

In addition to the activities in Indonesia, at GFZ Potsdam a SC3 installation processes data from both the GITEWS SC3 system and the GEOFON Extended Virtual Network (GEVN) presently comprising more than 700 stations worldwide. This new system became GFZ's central routine earthquake monitoring system as of August 2007, replacing the old purely automatic SeisComp2 (SC2) system (Hanka et al., 2008). In addition to the automatic solutions (produced for associations of at least 25 picks), now also manual solutions both for smaller events and manually updated revisions of the 


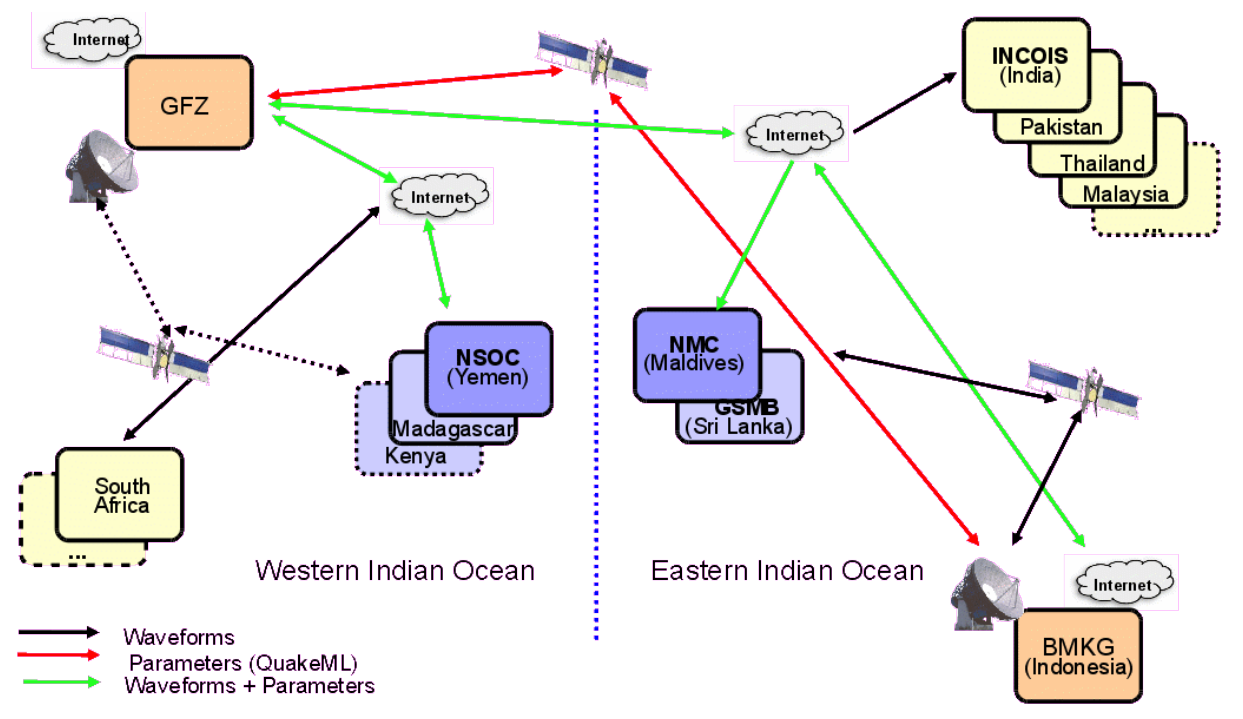

Fig. 7. Installation and interaction scheme of SeisComP3 systems in the Indian Ocean region.

larger events are issued. The high quality SC3 graphics modules allow quick and easy manual event review. The modules can be connected to a central SC3 server either locally e.g. from a local control centre multi-screen analyst working place - or remotely from ordinary laptop or desktop PCs at home or from elsewhere on the Internet. So far the manual interaction is done on a voluntary basis only and GFZ does not operate a full $24 / 7$ earthquake monitoring service or an on-call service. The new system and procedures helped also to improve the quality and quantity of the published events substantially with respect to the old system, while the dissemination of the automatic alerts is only slightly delayed due to the higher number of picks currently required. Also the number of disseminated false alarms and poor locations are reduced.

\subsection{Other SC3 installations across the globe}

After the successful implementation and optimization of SC3 at GFZ and BMKG other tsunami centres in the Indian Ocean, the Mediterranean and the SW Pacific were interested in using SC3 for their 24/7 earthquake monitoring. Dedicated computer hardware equipped with SC3 was delivered and on-site configuration and training was or is going to be provided soon to other GITEWS partner institutions in Yemen, the Maldives, Sri Lanka, Madagascar and Kenya. In addition, SC3 installation, configuration and training were also carried out for India, Pakistan, Thailand and Malaysia. For most other IOTWS member states, but also for ASEAN and other West and SW Pacific countries, special GITEWS trainings courses have been organized and SC3 is heavily used now beyond the primary GITEWS partner community. The overall situation with SC3 installations within IOTWS and their interactions is shown in Fig. 7.
In Europe, GFZ plays an active role in the NEAMTWS process. In contrast to the Indian Ocean, where it has only observer status in the IOTWS Intergovernmental Coordination Group (ICG), Germany is a regular member of the NEAMTWS/ICG. Due to potentially extremely short expected tsunami travel times, the situation for the Mediterranean, the Marmara and the Black Sea is arguably even more challenging than for Indonesia (Tinti, 2009). Although local tsunami warning is a national task rather than the responsibility of NEAMTWS, it is proposed to assist the planned VSAT based NEAMTWS seismic backbone network ( $\sim 90$ stations) by an Internet based extended VEBSN network (VEBSN plus selected non-public stations) to speed-up the earthquake monitoring. Since for German coasts no significant tsunami hazard exists, Germany does not plan to operate a national tsunami warning centre (NTWC) thus GFZ does currently not plan to operate a 24/7 seismic shift service. Instead, GFZ offered to act as a reliable automatic background data centre serving both joint real-time data feeds from its GEVN and the proposed future NEAMTWS backbone network and selected automatic processing results of its global earthquake monitoring system to the designated TWC's for visual verification, manual interaction and dissemination. In order to promote the implementation of a regional tsunami watch system GFZ initiated and coordinated an experimental data exchange among several potential regional tsunami watch centres. For this SC3 was installed at the designated national tsunami warning centres in Portugal, Spain, France, Greece, Turkey and Tunisia. Most of these centres are connected by a GFZ centred VPN (Virtual Private Network) system, through which public and private data streams and seismic parameters are securely exchanged. GFZ is also upgrading their GEOFON stations 
in the Mediterranean and NE Atlantic to GITEWS standard, which includes VSAT communication for NEAMTWS usage.

SeisComP3 is now in wide usage. Not only most other IOTWS and NEAMTWS tsunami warning centres or candidate centres are using it, but also many seismic services, scientific institutions and individual researchers have meanwhile obtained licenses for the freely available SeisComP3 package - in total $>100$ installations. It is used for various tasks including tsunami warning, local, regional and global earthquake monitoring or as software architecture framework for the development of new seismological methods and algorithms. The license is free for non-commercial usage and most of the code is open source.

\section{Current status and future for network expansion and data exchange}

The ability of earthquake monitoring for tsunami warning in the Indian Ocean countries has improved dramatically since the devastating 2004 tsunami and the GITEWS project and its earthquake monitoring group have made a major contribution to this. Before 2005 real-time seismic data processing was rare in this region, now most countries have their own tsunami warning centre which either perform their own earthquake monitoring or obtain such information from a regional centre. Modern real-time broadband seismic networks had previously been existing only in Malaysia, Singapore and Australia. Some single global stations were installed earlier by IRIS, GEOSCOPE and GEOFON. National seismic networks have been improved substantially now in Indonesia, but also in Thailand, India, Pakistan and South Africa. GITEWS has made a significant contribution to the Indonesian network and installed two stations each in the Indian Ocean rim countries Sri Lanka, Maldives, Yemen, Kenya and Madagascar, each currently lacking their own modern national seismic network. The data streams and archived data sets from all GITEWS stations as well as from all other GEOFON stations and more than 300 other GEVN stations are open and available to any user from the SeedLink or ArcLink servers at GFZ in Potsdam. Also the Australian, Malaysian and Singaporean data are open and freely distributed through the IRIS Data Management Center in Seattle. Direct data exchange among Indian Ocean countries still has to be improved. So far it has only been established among Indonesia and Malaysia and Thailand; all other data presently only flow through GFZ to other SC3 systems. Thus, GFZ presently acts as the major distribution point for Indian Ocean data, both public and non-public. Some countries only import foreign data but do not yet export any of their own data.

Direct parameter exchange is an even more difficult issue. Only GFZ has organized an import-export exchange of local SC3 solutions with the GITEWS partner systems. Currently no parametric data exchange is taking place among the partner institutions.

\section{Summary and outlook}

The earthquake monitoring system within the GITEWS project has largely achieved its design goals. Under difficult logistical conditions a regional seismological real-time network of 31 stations in Indonesia and five other Indian Ocean rim countries - including the three stations to be installed in 2011 - could be established. The earthquake monitoring capability in the region is significantly improved, in particular in respect to the potentially tsunami earthquake generating Sunda trench. In addition, the available real-time data streams from all other public networks within Indonesia and in neighbouring countries are collected, homogenized and uniformly processed in the Indonesian InaTEWS tsunami warning centre at BMKG in Jakarta. The SeisComP3 software allows BMKG to determine the basic seismological parameters for events in the Sunda trench and other parts of the Indonesian archipelago well within the envisaged $5 \mathrm{~min}$ limit. This deadline is due to the need to warn the population from near-field tsunamis with travel times as short as $20-30 \mathrm{~min}$. The SeisComp3 software has also been installed in the tsunami warning centres of many other Indian Ocean countries and enables these countries to exchange waveform data and seismic parameters both in real-time and from archives. The same is realized for Europe and the Mediterranean as well as for some other parts of the world. SeisComP3 provides also software architecture for the development of real-time processing and early warning methods and modules and is selected by several large projects in this field as their development platform (e.g. EC project NERIES, http://neries-eu.org and the German RAPID project, http://www.kooperation-international. de/countries/themes/nc/info/detail/data/47964/).

With SeisComP3, the previous GFZ prototype earthquake monitoring system was upgraded to a powerful system which issues rapid automatic but nevertheless reliable global and regional earthquake information and allows later interactive refinement and distribution of revised solutions. This system presently also acts as background system for many tsunami centres in the Indian Ocean and the NEAMTWS area. It provides earthquake information to the public as well as waveform data streams and internal processing results to connected partner institutions and enables these to improve their services. Following the GFZ example and making use of the free availability of the SeisComP3 software other seismic agencies have also improved the speed and quality of their services.

To avoid a loss of expertise after the completion of the GITEWS project GFZ encouraged members of the SC3 development team (Weber, B. and Becker, J.) to found at an early stage a small software and service company called "gempa" (Indonesian for quake; http://www.gempa. de). Also a SeisComP3 Users Group was founded and organized by GFZ and gempa, operating a dedicated web page (http://www.seiscomp3.org), mailing lists, and holding 
annual meetings. Since GFZ will have to reduce its future support to the GITEWS partners and SC3 users, the SC3 user community itself will have to take over a substantial part of the SC3 developments and applications.

A challenge for the future will be the long-term maintenance of the GITEWS infrastructure. As the project will officially end in spring 2011, the built-up stations and warning centres will be handed over to Indonesia and other host countries. Maintenance in the future will be mainly their responsibility. Nevertheless, GFZ is willing to give further advice and support, as resources permit. An active involvement in the NEAMTWS process is proposed but depending on the final system architecture and adequate funding.

Acknowledgements. The GITEWS project (German Indonesian Tsunami Early Warning System) is carried out by a large group of scientists and engineers from the GFZ German Research Centre for Geosciences (consortium leader) and its partners from, the Alfred Wegener Institute for Polar and Marine Research (AWI), the German Aerospace Center (DLR), the GKSS Research Centre, the German Marine Research Consortium (KDM), the Leibniz Institute for Marine Sciences (IFM-GEOMAR), the United Nations University (UNU), the Federal Institute for Geosciences and Natural Resources (BGR), the German Agency for Technical Cooperation (GTZ), as well as from Indonesia and other international partners. Funding is provided by the German Federal Ministry for Education and Research (BMBF), Grant03TSU01. This is GITEWS publication no. 103.

The authors would like to thank Alexander Rudloff, Frederik Tilmann, John Clinton, Lars Ottemöller, Rémy Bossu and an anonymous reviewer for their valuable comments and remarks which improved the manuscript substantially.

Edited by: A. Rudloff

Reviewed by: R. Bossu, L. Ottemöller, J. Clinton, and another anonymous referee

\section{References}

Bayer, B., Kind, R., Hoffmann, M., Yuan, X., and Meier, T.: Tracking Earthquake Rupture by P Wave Polarization Analysis, Geophys. J. Int., in review, 2010.

Behrens, J., Androsov, A., Babeyko, A. Y., Harig, S., Klaschka, F., and Mentrup, L.: A new multi-sensor approach to simulation assisted tsunami early warning, Nat. Hazards Earth Syst. Sci., 10, 1085-1100, doi:10.5194/nhess-10-1085-2010, 2010.

Bormann, P. and Saul, J.: The New IASPEI Standard Broadband Magnitude $m_{B}$, Seismol. Res. Lett., 79, 5, 698-706, 2008.

Bormann, P. and Saul, J.: A Fast, Non-saturating Magnitude Estimator for Great Earthquakes, Seismol. Res. Lett., 80, 5, 808-816, 2009.

Fleischer, J., Häner, R., Herrnkind, S., Kloth, A., Kriegel, U., Schwarting, H., and Wächter, J.: An integration platform for heterogeneous sensor systems in GITEWS - Tsunami Service Bus, Nat. Hazards Earth Syst. Sci., 10, 1239-1252, doi:10.5194/nhess-10-1239-2010, 2010.
Hanka, W. and Lauterjung, J.: GEOFON Involvement in EuroMed Tsunami Warning, EMSC Newsletter, 23, 14-15 April 2009.

Hanka, W., Heinloo, A., and Jäckel, K.-H.: Networked Seismographs: GEOFON Real-Time data Distribution, ORFEUS Electronic Newsletter, 2, 3, http://www.orfeus-eu.org, 2000.

Hanka, W., Lauterjung, J., and GITEWS Team: GEOFON and the German Indian Ocean Tsunami Warning System, IRIS Newsletter, 2006, 2, 8-9, 2006.

Hanka, W., Saul, J., Weber, B., Becker, J., and GITEWS Team: Timely Regional Tsunami Warning and Rapid Global Earthquake Monitoring, ORFEUS Newsletter, 8, 1, http://www. orfeus-eu.org, 2008.

Johnson, C. E., Bittenbinder, A., Bogaert, B., Dietz, L., and Kohler, W.: Earthworm: A flexible approach to seismic network processing, IRIS Newsletter 14, 2, 1-4, 1995.

Krueger, F. and Ohrnberger, M.: Spatio-temporal source characteristics of the 26 December 2004 Sumatra earthquake as imaged by teleseismic broadband arrays, Geophys. Res. Lett., 32, L24312, doi:10.1029/2005GL023939, 2005.

Lauterjung, J., Münch, U., and Rudloff, A.: The challenge of installing a tsunami early warning system in the vicinity of the Sunda Arc, Indonesia, Nat. Hazards Earth Syst. Sci., 10, 641646, doi:10.5194/nhess-10-641-2010, 2010.

Luckett, R., Ottemöller, L., and Whitmore, P: A Tsunami Warning System for the Northewast Atlantic, ORFEUS Newsletter, 8, 1, http://www.orfeus-eu.org, 2008.

Roessler, D., Krueger, F., Ohrnberger, M., and Ehlert, L.: Rapid characterisation of large earthquakes by multiple seismic broadband arrays, Nat. Hazards Earth Syst. Sci., 10, 923-932, doi:10.5194/nhess-10-923-2010, 2010.

Rudloff, A., Lauterjung, J., Münch, U., and Tinti, S.: Preface "The GITEWS Project (German-Indonesian Tsunami Early Warning System)", Nat. Hazards Earth Syst. Sci., 9, 1381-1382, doi:10.5194/nhess-9-1381-2009, 2009.

Stein, S. and Okal, E. A.: Speed and Size of the Sumatra earthquake, Nature, 434, 581-582, 2005.

Steinmetz, T., Raape, U., Teßmann, S., Strobl, C., Friedemann, M., Kukofka, T., Riedlinger, T., Mikusch, E., and Dech, S.: Tsunami early warning and decision support, Nat. Hazards Earth Syst. Sci., 10, 1839-1850, doi:10.5194/nhess-10-1839-2010, 2010.

Tinti, S.: The Role of ICG/NEAMTWS for the Implementation of the Tsunami Warning System (TWS) in the European Region, EMSC Newsletter, 23, 6-9 April 2009.

Tsuboi, S., Whitmore, P. M., and Solokowski, T. J.: Application of $M_{\mathrm{wp}}$ to deep and teleseismic earthquakes, Bull. Seismol. Soc. Am., 89, 1, 1345-1351, 1999.

Van Eck, T., Trabant, C., Dost, B., Hanka, W., and Giardini, D.: Setting up a virtual broadband seismograph network across Europe, EOS Trans. AGU, 85, 125-129, 2004.

Whitmore, P. M., Sokolowski, T. J., Tsuboi, S., and Hirshorn, B.: Magnitude-dependent correction for $M_{\mathrm{wp}}$, Science of Tsunami Hazards, 20(4), 187-192, 2002. 